\title{
Association between DNA mismatch repair gene polymorphisms and platinum-based chemotherapy toxicity in non-small cell lung cancer patients
}

\author{
Jun-Yan Liu' ${ }^{1}$, Chen-Yue Qian ${ }^{2,3,4}$, Yuan-Feng Gao ${ }^{2,3,4}$, Juan Chen ${ }^{2,3,4}$, Hong-Hao Zhou ${ }^{2,3,4}$ and Ji-Ye Yin ${ }^{2,3,4^{*}}$
}

\begin{abstract}
Background: Chemotherapy toxicity is a serious problem from which non-small cell lung cancer (NSCLC) patients suffer. The mismatch repair (MMR) system is associated with platinum-based chemotherapy toxicity in NSCLC patients. In this study, we aimed to investigate the relationship between genetic polymorphisms in the MMR pathway and platinum-based chemotherapy toxicity in NSCLC patients.

Methods: A total of 220 Chinese lung cancer patients who received at least two cycles of platinum-based chemotherapy were recruited for this study. Toxicity was evaluated in each patient after two cycles of chemotherapy. A total of 44 single nucleotide polymorphisms were selected to investigate their associations with platinum-based chemotherapy toxicity.

Results: MutS homolog 2 (MSH2) rs6544991 [odds ratio (OR) 2.98, 95\% confidence interval (Cl) $1.20-7.40, P=0.019$ ] was associated with gastrointestinal toxicity in the dominant model; MSH3 rs6151627 (OR 2.38, 95\% Cl 1.23-4.60, $P=0.010)$, rs6151670 (OR 2.05, 95\% Cl 1.07-3.93, $P=0.031)$, and rs 7709909 (OR 2.38, 95\% Cl 1.23-4.64, $P=0.010)$ were associated with hematologic toxicity in the dominant model. Additionally, MSH5 rs805304 was significantly associated with overall toxicity (OR 2.21, 95\% Cl 1.19-4.09, $P=0.012)$, and MSH5 rs707939 was significantly associated with both overall toxicity $(\mathrm{OR} 0.42,95 \% \mathrm{Cl} 0.23-0.76, P=0.004)$ and gastrointestinal toxicity $(\mathrm{OR} 0.44,95 \% \mathrm{Cl} 0.20-0.96$, $P=0.038$ in the dominant model.
\end{abstract}

Conclusion: Genetic polymorphisms in the MMR pathway are potential clinical markers for predicting chemotherapy toxicity in NSCLC patients.

Keywords: DNA mismatch repair, Lung cancer, Chemotherapy toxicity, Platinum

\section{Background}

Non-small cell lung cancer (NSCLC) is a common cancer and the main cause of cancer-related mortality worldwide [1-5]. Although many new target drugs, such as gefitinib and erlotinib, have been used to treat NSCLC, cytotoxic drugs, such as platinum, are still used as firstline agents in the treatment of NSCLC $[6,7]$. However,

\footnotetext{
*Correspondence: yinjiye@csu.edu.cn

2 Department of Clinical Pharmacology, Xiangya Hospital, Central South University, Changsha 410008, Hunan, P. R. China

Full list of author information is available at the end of the article
}

adverse drug reactions, such as nephrotoxicity, hepatotoxicity, hematologic toxicity, and gastrointestinal toxicity, are major obstacles to successful treatment [8-10]. Thus, it is important to identify biomarkers that can be used to predict platinum-based chemotherapeutic toxicity [11].

DNA mismatch repair (MMR) is a key DNA repair system $[12,13]$. It is highly conserved and plays an important role in correcting errors generated during DNA replication [14, 15]. MMR proteins interact with one another to form protein complexes that recognize and digest mismatched DNA segments and ultimately fill mismatch 
gaps [16]. Briefly, MutL homolog 1 (MLH1) dimerizes with postmeiotic segregation increased 1 (PMS1), PMS2, or MLH3 to form the MLH1/PMS2 (MutL $\alpha$ ), MLH1/PMS1 (MutL $\beta)$, or MLH1/MLH3 (MutLy) heterodimer and MutS homolog 2 (MSH2) dimerizes with MSH6 or MSH3 to form the MSH2/MSH6 (MutSa) or MSH2/MSH3 (MutS $\beta$ ) heterodimer so as to bind the DNA helix and recognize DNA mismatches. Together with the abovementioned MutL complexes, the MutS $\alpha$ complex guides the repair of single-base and small-loop mismatches, whereas the MutS $\beta$ complex guides the repair of small- to large-loop mismatches [16-19]. Thus, $M u t S \alpha$ and $M u t L \alpha$ are key proteins in the MMR system and are responsible for mismatch detection and subsequent repair event coordination [20,21].

There are several partially overlapping DNA repair pathways, including base excision repair (BER), nucleotide excision repair (NER), double-strand break repair (DSBR), and MMR [22]. A previous study showed that mutations in DNA repair genes affect the effectiveness and toxicity of platinum-based chemotherapy in NSCLC patients [23]. MMR plays a key role in maintaining genomic stability through the highly conserved biological pathway. It is an important determinant of platinum cellular toxicity. The formation of platinum/DNA adducts blocks replication and transcription of DNA, and the MMR system plays an important role in removing these adducts. MMR defects lead to replication and recombination errors and cause 6-thioguanine (6-TG)- and O6-methylguanine-induced toxicity in DNA glycosylasedeficient cells [24]. It has been reported that mutations in MMR pathway genes may be associated with platinumbased chemotherapy toxicity in NSCLC patients $[23,25]$. In addition, mutations in MMR genes, particularly those in $M S H 3$ and $M S H 5$, may be associated with the risk of lung cancer and even lead to increased alkylation tolerance [26].

Our previous studies showed that genetic polymorphisms were useful clinical markers for chemotherapy response and toxicity prediction in lung cancer patients [9, 27-29]. To investigate the relationship between MMR pathway genetic polymorphisms and platinum-induced toxicity, we evaluated 6 MMR genes (MLH1, MSH2, MSH3, MSH4, MSH5, and MSH6) in Chinese NSCLC patients.

\section{Methods}

\section{Study subjects}

All patients met the following inclusion criteria were selected: (1) patients between 18 and 80 years old; (2) patients newly diagnosed with NSCLC, including adenocarcinoma or squamous cell carcinoma, with histological or cytological examination at the Affiliated Cancer
Hospital or Xiangya Hospital of Central South University (Changsha, Hunan, China) between December 2012 and December 2015; (3) patients who received at least two cycles of platinum-based chemotherapy, e.g., cisplatin or carboplatin chemotherapy; (4) patients with no history of chemotherapy or radiotherapy; and (5) patients with no history of surgery before or during chemotherapy. Patients with active infections or other concomitant malignancies were excluded.

All patients provided written informed consent before they participated in this study. The study protocol was approved by the Ethics Committee of Xiangya School of Medicine, Central South University (approval number: CTXY-110008-1). This clinical research project was approved by the Chinese Clinical Trial Registry under the following registration number: ChiCTR-RNC-12002892 (http://www.chictr.org/cn/).

\section{SNP selection, DNA extraction, and genotyping}

All single nucleotide polymorphisms (SNPs) were selected by Haploview (Broad Institute, Cambridge, MA, USA) using pair-wise tagging with default settings (pairwise $r^{2}$ threshold $=0.8$ ). The following SNPs were eligible for further study: SNPs with a minor allele frequency (MAF) $\geq 5 \%$ in the Han Chinese population and SNPs in Hardy-Weinberg equilibrium (HWE) $(P>0.05)$.

All blood samples were collected in the morning and stored at $-20^{\circ} \mathrm{C}$ for $4 \mathrm{~h}$. Genomic DNA was isolated using a Genomic DNA Purification Kit (Promega, Madison, WI, USA) and stored at $-20^{\circ} \mathrm{C}$ before use. Genotyping was conducted using a Sequenom MassARRAY Genotyping Platform (Sequenom, San Diego, CA, USA).

\section{Toxicity evaluation criteria}

Platinum-based chemotherapy-induced toxicity was estimated according to the National Cancer Institute Common Toxicity Criteria, Version 3.0. The toxicity intensity was graded on a scale of $1-5$ as follows: grade 1, mild adverse events; grade 2, moderate adverse events; grade 3 , severe adverse events; grade 4, life-threatening or disabling adverse events; and grade 5, death related to adverse events. We recruited patients experiencing grade 0 to grade 4 toxicity, and they were divided into two categories. Patients experiencing grade $0-2$ adverse events were classified into the low-toxicity category, whereas patients with grades 3 and 4 adverse events were classified into the severe toxicity category.

\section{Statistical analysis}

The genotype frequencies observed among all patients were compared with their expected frequencies under Hardy-Weinberg equilibrium using a $x^{2}$ test $(P>0.05)$. Sex, age, smoking status, tumor histology, clinical stage, 
and Eastern Cooperative Oncology Group (ECOG) performance status were considered potential covariates for logistic regression. All analyses were performed using PLINK (version 1.07, http://pngu.mgh.harvard.edu/purcell/plink/) and SPSS 13.0 software (SPSS Inc, Chicago, IL, USA). Odds ratios (OR) and their 95\% confidence intervals (95\% CI) were used to assess the association between treatment outcomes and gene polymorphisms. $P<0.05$ was considered statistically significant.

\section{Results}

Patient characteristics

A total of 220 patients who received first-line platinumbased chemotherapy were recruited for this study. A total of 44 SNPs were genotyped in these patients, and 37 of them were in HWE $(P>0.05)$ and exhibited an MAF $\geq 5 \%$. The basic information of these SNPs and the clinical characteristics of these lung cancer patients are summarized in Tables 1 and 2, respectively. Hematologic,

Table 1 Thirty-seven single nucleotide polymorphisms (SNPs) in DNA mismatch repair (MMR) genes

\begin{tabular}{|c|c|c|c|c|c|c|}
\hline Gene & SNP (rs number) & Allele & Localization & Call rate (\%) & MAF & HWE \\
\hline \multirow[t]{3}{*}{ MLHI } & rs10849 & $\mathrm{G} / \mathrm{A}$ & $3^{\prime}-$ UTR & 99.55 & 0.09 & 0.764 \\
\hline & rs1540354 & $\mathrm{A} / \mathrm{T}$ & Intron & 97.73 & 0.68 & 0.635 \\
\hline & rs749072 & $\mathrm{T} / \mathrm{C}$ & Intron & 97.73 & 0.62 & 0.217 \\
\hline \multirow[t]{9}{*}{ MSH2 } & rs10191478 & $\mathrm{T} / \mathrm{G}$ & Intron & 97.73 & 0.20 & 0.264 \\
\hline & rs12999145 & $\mathrm{A} / \mathrm{G}$ & Intron & 98.64 & 0.53 & 0.783 \\
\hline & rs13019654 & $\mathrm{G} / \mathrm{T}$ & Intron & 96.82 & 0.28 & 0.710 \\
\hline & rs1981929 & $\mathrm{G} / \mathrm{A}$ & Intron & 97.27 & 0.86 & 0.309 \\
\hline & rs2303428 & $\mathrm{A} / \mathrm{C}$ & Intron & 98.64 & 0.33 & 0.234 \\
\hline & rs4608577 & $\mathrm{T} / \mathrm{G}$ & Intron & 93.18 & 0.13 & 0.106 \\
\hline & rs4952887 & $\mathrm{C} / \mathrm{T}$ & Intron & 98.18 & 0.15 & 0.124 \\
\hline & rs6544991 & $\mathrm{A} / \mathrm{C}$ & Intron & 95.00 & 0.36 & 0.605 \\
\hline & rs7602094 & $\mathrm{T} / \mathrm{C}$ & Intron & 95.91 & 0.66 & 0.560 \\
\hline \multirow[t]{10}{*}{ MSH3 } & rs245340 & $\mathrm{A} / \mathrm{C}$ & Intron & 97.73 & 0.24 & 0.203 \\
\hline & rs245346 & $\mathrm{T} / \mathrm{C}$ & Intron & 97.73 & 0.45 & 0.738 \\
\hline & rs26778 & $\mathrm{A} / \mathrm{T}$ & Intron & 96.36 & 0.59 & 0.713 \\
\hline & rs26784 & $\mathrm{T} / \mathrm{C}$ & Intron & 97.73 & 0.37 & 0.860 \\
\hline & rs3816729 & $\mathrm{A} / \mathrm{G}$ & Intron & 96.36 & 0.30 & 0.927 \\
\hline & rs6151627 & $A / G$ & Intron & 99.09 & 0.29 & 0.554 \\
\hline & rs6151670 & $C / G$ & Intron & 98.18 & 0.28 & 0.258 \\
\hline & rs6151892 & T/A & Intron & 99.09 & 0.33 & 0.729 \\
\hline & rs6151914 & $C / T$ & Intron & 97.73 & 0.09 & 0.065 \\
\hline & rs7709909 & $C / T$ & Intron & 99.09 & 0.31 & 0.572 \\
\hline \multirow[t]{2}{*}{ MSH4 } & rs3806162 & $\mathrm{T} / \mathrm{G}$ & $5^{\prime}$ near gene & 99.09 & 0.22 & 0.393 \\
\hline & rs5745532 & $\mathrm{T} / \mathrm{C}$ & Intron & 99.09 & 0.75 & 0.112 \\
\hline \multirow[t]{6}{*}{ MSH5 } & rs3117572 & $\mathrm{G} / \mathrm{A}$ & Intron & 98.64 & 0.28 & 0.103 \\
\hline & rs409558 & $\mathrm{A} / \mathrm{G}$ & Intron & 100.00 & 0.13 & 0.312 \\
\hline & rs707937 & $C / G$ & Intron & 96.82 & 0.42 & 0.369 \\
\hline & rs707938 & $\mathrm{A} / \mathrm{G}$ & Synonymous & 97.27 & 0.30 & 0.428 \\
\hline & rs707939 & $\mathrm{G} / \mathrm{T}$ & Intron & 100.00 & 0.39 & 0.097 \\
\hline & rs805304 & $C / A$ & $5^{\prime}$ near gene & 98.18 & 0.69 & 0.448 \\
\hline \multirow[t]{7}{*}{ MSH6 } & rs2020910 & T/A & Intron & 99.09 & 0.17 & 0.893 \\
\hline & rs2348244 & $\mathrm{T} / \mathrm{C}$ & Intron & 99.09 & 0.39 & 0.856 \\
\hline & rs2710163 & $\mathrm{T} / \mathrm{C}$ & Intron & 98.18 & 0.70 & 0.856 \\
\hline & rs3136329 & $\mathrm{T} / \mathrm{C}$ & Intron & 97.27 & 0.13 & 0.108 \\
\hline & rs3732190 & $\mathrm{G} / \mathrm{A}$ & Intron & 95.91 & 0.09 & 0.933 \\
\hline & rs6713506 & $\mathrm{G} / \mathrm{A}$ & Intron & 98.64 & 0.06 & 0.852 \\
\hline & rs6742522 & $\mathrm{G} / \mathrm{A}$ & Intron & 99.09 & 0.11 & 0.259 \\
\hline
\end{tabular}


Table 2 The clinical characteristics of the 220 non-small cell lung cancer (NSCLC) patients

\begin{tabular}{|c|c|}
\hline Variate & Number of patients [cases (\%)] \\
\hline Total & 220 \\
\hline \multicolumn{2}{|l|}{ Age (years) } \\
\hline$\leq 55$ & $93(42.3)$ \\
\hline$>55$ & $127(57.7)$ \\
\hline \multicolumn{2}{|l|}{ Smoking status } \\
\hline Never & $95(43.2)$ \\
\hline Ever & $125(56.8)$ \\
\hline \multicolumn{2}{|l|}{ Gender } \\
\hline Male & $165(75.0)$ \\
\hline Female & $55(25.0)$ \\
\hline \multicolumn{2}{|l|}{ ECOG PS } \\
\hline $0-1$ & $39(17.7)$ \\
\hline 2 & $181(82.3)$ \\
\hline \multicolumn{2}{|l|}{ Histological type } \\
\hline Adenocarcinoma & $108(49.1)$ \\
\hline Squamous cell carcinoma & $112(50.9)$ \\
\hline \multicolumn{2}{|l|}{ Stage } \\
\hline$|-| \mid$ & $8(3.6)$ \\
\hline III-IV & $212(96.4)$ \\
\hline \multicolumn{2}{|l|}{ Platinum-based drug } \\
\hline Cisplatin & $37(16.8)$ \\
\hline Carboplatin & $183(83.2)$ \\
\hline \multicolumn{2}{|l|}{ Chemotherapy regimen } \\
\hline Platinum-gemcitabine & $112(50.9)$ \\
\hline Platinum-pemetrexed & $68(30.9)$ \\
\hline Platinum-paclitaxel & $23(10.4)$ \\
\hline Platinum-docetaxel & $12(5.5)$ \\
\hline Platinum-navelbine & $5(2.3)$ \\
\hline \multicolumn{2}{|l|}{ Severe toxicity } \\
\hline Total & 79 (35.9) \\
\hline Hematologic toxicity & $55(25.0)$ \\
\hline Gastrointestinal toxicity & $31(14.1)$ \\
\hline
\end{tabular}

ECOG Eastern Cooperative Oncology Group, PS performance status

gastrointestinal, and overall toxicity were assessed after the first two cycles of chemotherapy. Severe overall toxicity occurred in 79 (35.9\%) patients. Among them, severe hematologic and gastrointestinal toxicity occurred in 55 $(25.0 \%)$ and $31(14.1 \%)$ patients, respectively.

\section{Association between MMR gene polymorphisms and toxicity}

The genotypes of the 37 SNPs in 6 DNA MMR genes were determined in the 220 patients. The results are summarized in Additional file 1: Table S1. Six SNPs exhibited significant associations with toxicity (Table 3). MSH2 rs6544991 (OR 2.98, 95\% CI 1.20-7.40, $P=0.019$ ) was associated with gastrointestinal toxicity in the dominant model. MSH3 rs6151627 (OR 2.38, 95\% CI 1.23-4.60, $P=0.010$ ), MSH3 rs6151670 (OR 2.05, 95\% CI $1.07-$ $3.93, P=0.031$ ), and $M S H 3$ rs7709909 (OR 2.38, 95\% CI $1.23-4.64, P=0.010$ ) were associated with hematologic toxicity in the dominant model. MSH5 rs805304 was significantly associated with overall toxicity (additive model: OR 1.66, 95\% CI 1.04-2.65, $P=0.033$; dominant model: OR 2.21, 95\% CI 1.19-4.09, $P=0.012$ ). MSH5 rs707939 was significantly associated with overall toxicity (additive model: OR $0.45,95 \%$ CI $0.28-0.73, P=0.001$; dominant model: OR $0.42,95 \%$ CI $0.23-0.76, P=0.004$; recessive model: OR $0.27,95 \%$ CI $0.09-0.84, P=0.023$ ) and gastrointestinal toxicity (additive model: OR $0.46,95 \% \mathrm{CI}$ $0.24-0.88, P=0.020$; dominant model: OR $0.44,95 \% \mathrm{CI}$ $0.20-0.96, P=0.038$ ).

\section{Stratification analyses}

Stratification analyses were performed to investigate the associations between all SNPs that were significantly associated with overall toxicity. Patients were stratified by cancer type (squamous cell carcinoma or adenocarcinoma), age ( $\leq 55$ years or $>55$ years), smoking status (non-smoker or smoker), and sex (male or female). As shown in Fig. 1, MSH5 rs707939 exhibited significant associations with squamous cell carcinoma (additive model: OR $0.25,95 \%$ CI $0.12-0.51, P<0.001$; dominant model: OR $0.20,95 \%$ CI $0.08-0.46, P<0.001$; recessive model: OR $0.19,95 \%$ CI $0.04-0.88, P=0.034)$, patients $\leq 55$ years of age (additive model: OR $0.50,95 \% \mathrm{CI}$ $0.29-0.85, P=0.011$; dominant model: OR $0.48,95 \% \mathrm{CI}$ 0.25-0.93, $P=0.030$ ), smokers (additive model: OR 0.44, 95\% CI 0.24-0.81, $P=0.009$; dominant model: OR 0.37, 95\% CI $0.17-0.80, P=0.011$ ), and male patients (additive model: OR $0.50,95 \%$ CI $0.29-0.85, P=0.011$; dominant model: OR $0.48,95 \% \mathrm{CI} 0.25-0.93, P=0.030$ ). No significant associations were noted for any other SNPs. Taken together, these results indicate that $\mathrm{T}$ allele carriers of MSH5 rs707939 polymorphism have better tolerance to gastrointestinal toxicity and overall toxicity than carriers of other polymorphisms.

\section{Discussion}

In this study, we investigated whether polymorphisms of MMR genes (MLH1, MSH2, MSH3, MSH4, MSH5, and MSH6) were associated with platinum-based chemotherapy toxicity in 220 NSCLC patients. We evaluated the associations between these gene polymorphisms and gastrointestinal, hematologic, and overall toxicities. Our results showed that $M S H 2$ rs6544991 was associated with gastrointestinal toxicity, MSH3 rs6151627, rs6151670, and rs7709909 were associated with hematologic toxicity, and MSH5 rs707939 and rs805304 were associated with gastrointestinal toxicity and overall toxicity. 
Table 3 Associations between MMR gene polymorphisms and platinum-based chemotherapy toxicity in the 220 NSCLC patients

\begin{tabular}{|c|c|c|c|c|c|c|c|c|}
\hline \multirow[t]{2}{*}{ Toxicity } & \multirow[t]{2}{*}{ Gene } & \multirow[t]{2}{*}{ SNP } & \multicolumn{2}{|l|}{ Additive model } & \multicolumn{2}{|l|}{ Dominant model } & \multicolumn{2}{|c|}{ Recessive model } \\
\hline & & & OR $(95 \% \mathrm{Cl})$ & $P$ & OR $(95 \% \mathrm{Cl})$ & $P$ & OR $(95 \% \mathrm{Cl})$ & $P$ \\
\hline \multirow[t]{6}{*}{ Overall } & MSH2 & rs6544991 & $1.18(0.77-1.79)$ & 0.447 & $1.39(0.76-2.55)$ & 0.290 & $1.02(0.44-2.33)$ & 0.973 \\
\hline & MSH3 & rs6151627 & $1.20(0.77-1.86)$ & 0.419 & $1.49(0.83-2.65)$ & 0.181 & $0.77(0.27-2.17)$ & 0.618 \\
\hline & & rs6151670 & $1.14(0.73-1.76)$ & 0.572 & $1.37(0.76-2.45)$ & 0.293 & $0.75(0.27-2.13)$ & 0.593 \\
\hline & & rs7709909 & $1.21(0.79-1.87)$ & 0.380 & $1.51(0.84-2.71)$ & 0.163 & $0.83(0.31-2.19)$ & 0.703 \\
\hline & MSH5 & rs707939 & $0.45(0.28-0.73)$ & 0.001 & $0.42(0.23-0.76)$ & 0.004 & $0.27(0.09-0.84)$ & 0.023 \\
\hline & & rs805304 & $1.66(1.04-2.65)$ & 0.034 & $2.21(1.19-4.09)$ & 0.012 & $1.21(0.44-3.34)$ & 0.716 \\
\hline \multirow[t]{6}{*}{ Hematologic } & MSH2 & rs6544991 & $1.01(0.64-1.61)$ & 0.957 & $0.97(0.50-1.87)$ & 0.919 & $1.12(0.45-2.77)$ & 0.805 \\
\hline & MSH3 & rs6151627 & $1.55(0.96-2.50)$ & 0.074 & $2.38(1.23-4.60)$ & 0.010 & $0.75(0.23-2.44)$ & 0.635 \\
\hline & & rs6151670 & $1.42(0.88-2.29)$ & 0.153 & $2.05(1.07-3.93)$ & 0.032 & $0.75(0.23-2.43)$ & 0.630 \\
\hline & & rs7709909 & $1.55(0.97-2.49)$ & 0.067 & $2.38(1.23-4.64)$ & 0.010 & $0.87(0.30-2.58)$ & 0.808 \\
\hline & MSH5 & rs707939 & $0.68(0.41-1.12)$ & 0.128 & $0.66(0.35-1.28)$ & 0.219 & $0.50(0.16-1.54)$ & 0.225 \\
\hline & & rs805304 & $1.37(0.83-2.27)$ & 0.223 & $1.99(1.01-3.90)$ & 0.047 & $0.60(0.16-2.20)$ & 0.436 \\
\hline \multirow[t]{6}{*}{ Gastrointestinal } & MSH2 & rs6544991 & $1.56(0.90-2.69)$ & 0.113 & $2.98(1.20-7.40)$ & 0.019 & $0.88(0.28-2.76)$ & 0.827 \\
\hline & MSH3 & rs6151627 & $0.63(0.33-1.20)$ & 0.161 & $0.54(0.24-1.19)$ & 0.128 & $0.66(0.14-3.02)$ & 0.592 \\
\hline & & rs6151670 & $0.67(0.35-1.27)$ & 0.220 & $0.59(0.27-1.32)$ & 0.199 & $0.64(0.14-2.94)$ & 0.568 \\
\hline & & rs7709909 & $0.62(0.33-1.18)$ & 0.145 & $0.55(0.25-1.20)$ & 0.132 & $0.58(0.13-2.63)$ & 0.481 \\
\hline & MSH5 & rs707939 & $0.46(0.24-0.88)$ & 0.020 & $0.44(0.20-0.96)$ & 0.038 & $0.21(0.03-1.65)$ & 0.139 \\
\hline & & rs805304 & $1.64(0.90-2.97)$ & 0.105 & $1.86(0.83-4.20)$ & 0.133 & $1.85(0.56-6.14)$ & 0.314 \\
\hline
\end{tabular}

OR odds ratio, 95\% Cl 95\% confidence interval; other abbreviations as in Table 1

A previous study showed that MSH2 was a key protein that influenced 6-thioguanine (6-TG)- and $\mathrm{O}^{6}$-methylguanine-induced toxicity in DNA glycosylase-deficient cells, indicating that $M S H 2$ plays an important role in attenuating oxidative DNA damage [24]. In our study, $\mathrm{C}$ allele carriers of rs6544991, which features an A/C single-nucleotide variation located in the intron area of $M S H 2$, exhibited poor gastrointestinal toxicity tolerance after being treated with platinum-based chemotherapy. We speculated that this SNP may affect the ability of $\mathrm{MSH} 2$ to remove platinum adducts. In addition, our results showed that $M S H 3$ rs6151627 $\mathrm{G}$ allele carriers, rs6151670 $\mathrm{G}$ allele carriers, and rs7709909 T allele carriers exhibited poor hematologic toxicity tolerance after being treated with platinum-based chemotherapy. MSH3 rs6151627 is an A/G single-nucleotide variation, rs6151670 is a $\mathrm{C} / \mathrm{G}$ single-nucleotide variation, and rs7709909 is a $\mathrm{C} / \mathrm{T}$ single-nucleotide variation. All of these polymorphisms are intron variants of MSH3. Methylation of the MSH3 promoter is involved in esophageal tumorigenesis, suggesting that it plays an important role in modulating cell chemosensitivity. As a DNA MMR gene, MSH3 forms the MutS $\beta$ heteroduplex with MSH2. The MSH2/MSH3 heterodimer is an ATPase that plays a critical role in mismatch recognition and repair initiation. It binds to DNA mismatches by recognizing 2- to 13-bp insertion-deletion loops [30]. The three SNPs are speculated to affect the function of MSH3; however, the underlying mechanism is still unclear.

Another important finding of our study was that $\mathrm{MSH} 5$ polymorphisms were significantly related to overall toxicity. MSH5 rs707939 T allele carriers exhibited better gastrointestinal and overall toxicity tolerance after being treated with platinum-based chemotherapy. Moreover, among MSH5 rs707939 T allele carriers, stratification analysis showed that male patients, patients $\leq 55$ years old, smokers, and patients diagnosed with squamous cell carcinoma faced a lower risk of overall severe toxicity than their counterparts. All these results indicated that MSH5 rs707939 was associated with reduced cisplatin-induced gastrointestinal and overall toxicities in NSCLC patients. In addition, MSH5 rs805304 was also significantly associated with gastrointestinal and overall toxicities. It is noteworthy that rs707939 is a G/T single-nucleotide variation in the intron of MSH5. Previous studies suggested that mutations in MSH5 result in alkylation tolerance in mammalian cells, which is associated with lung cancer risk [26, 31]. Thus, rs707939 and rs805304 may also affect MSH5 activity.

As far as we know, DNA MMR gene defects lead to MMR function loss, which increases the spontaneous 


\begin{tabular}{|c|c|c|c|}
\hline Additive variable & rs707939 & OR $(95 \% \mathrm{CI})$ & $P$ \\
\hline Squamous cell carcinoma & 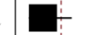 & $0.25(0.12-0.51)$ & $<0.001$ \\
\hline Adenocarcinoma & & $0.84(0.44-1.63)$ & 0.614 \\
\hline$\leq 55$ years & & $0.50(0.29-0.85)$ & 0.011 \\
\hline$>55$ years & & $0.42(0.17-1.01)$ & 0.054 \\
\hline Non-smoker & & $0.50(0.25-1.01)$ & 0.053 \\
\hline Smoker & & $0.44(0.24-0.81)$ & 0.009 \\
\hline Male & & $0.50(0.29-0.85)$ & 0.011 \\
\hline Female & & $0.42(0.17-1.01)$ & 0.054 \\
\hline-1.63 & 0 & 1.63 & \\
\hline Dominant variable & rs707939 & OR $(95 \% \mathrm{CI})$ & $P$ \\
\hline Squamous cell carcinoma & & $0.20(0.08-0.46)$ & $<0.001$ \\
\hline Adenocarcinoma & & $1.02(0.42-2.51)$ & 0.960 \\
\hline$\leq 55$ years & & $0.48(0.25-0.93)$ & 0.030 \\
\hline$>55$ years & & $0.38(0.12-1.17)$ & 0.090 \\
\hline Non-smoker & & $0.54(0.22-1.31)$ & 0.169 \\
\hline Smoker & & $0.37(0.17-0.80)$ & 0.011 \\
\hline Male & & $0.48(0.25-0.93)$ & 0.030 \\
\hline Female & & $0.38(0.12-1.17)$ & 0.090 \\
\hline-2.51 & 0 & 2.51 & \\
\hline Recessive variable & rs707939 & OR $(95 \% \mathrm{CI})$ & $P$ \\
\hline Squamous cell carcinoma & 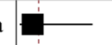 & $0.19(0.04-0.88)$ & 0.034 \\
\hline Adenocarcinoma & & $0.44(0.09-2.08)$ & 0.298 \\
\hline$\leq 55$ years & & $0.30(0.08-1.08)$ & 0.066 \\
\hline$>55$ years & & $0.21(0.02-1.85)$ & 0.160 \\
\hline Non-smoker & $=$ & $0.16(0.02-1.30)$ & 0.087 \\
\hline Smoker & & $0.37(0.10-1.41)$ & 0.145 \\
\hline Male & & $0.30(0.08-1.08)$ & 0.066 \\
\hline Female & & $0.21(0.02-1.85)$ & 0.160 \\
\hline
\end{tabular}

Fig. 1 Stratification analyses of the associations between the MutS homolog 5 (MSH5) rs707939 polymorphism and overall platinumbased chemotherapy toxicity in the 220 non-small cell lung cancer patients using the additive, dominant, and recessive models. Each box and horizontal line represents an odds ratio (OR) and a 95\% confidence interval (Cl) mutation frequencies of cells. Cell mutation phenotypes are thought to result in malignant transformation and cause continuous accumulation of gene mutation events. Many error messages across the entire genome eventually affect the effectiveness and toxicity of chemotherapy. However, the detailed mechanisms underlying the effects of these SNPs on gene function need to be studied further.

\section{Conclusions}

Our findings indicate that carriers of the MSH5 rs707939 $\mathrm{T}$ allele, the $M S H 2$ rs6544991 $\mathrm{C}$ allele, the $M S H 3$ rs6151627 and rs6151670 $\mathrm{G}$ alleles, and the MSH3 rs7709909 $\mathrm{T}$ allele have poor toxicity tolerance. Therefore, these polymorphisms are potential clinical markers for predicting platinum-based chemotherapy toxicity in Chinese NSCLC patients. However, a study with a larger sample size is needed to validate these findings in the future.

\section{Additional file}

Additional file 1: Table S1. Associations between $37 \mathrm{MMR} \mathrm{SNP}$ and platinum-based chemotherapy toxicity (Original Dates Analysis).

\section{Authors' contributions}

$H H Z$, JYL, JC, and JYY conceived and designed the experiments. JYL and CYQ performed the experiments. JYY, CYQ, JC, and JYY analyzed the data. JYY, YFG, and CYQ wrote the manuscript. JYY edited the manuscript. All authors read and approved the final manuscript.

\section{Author details}

${ }^{1}$ Xiangya School of Medicine, Central South University, Changsha 410008, Hunan, P. R. China. ${ }^{2}$ Department of Clinical Pharmacology, Xiangya Hospital, Central South University, Changsha 410008, Hunan, P. R. China. ${ }^{3}$ Institute of Clinical Pharmacology, Hunan Key Laboratory of Pharmacogenetics, Central South University, Changsha 410078, Hunan, P. R. China. ${ }^{4}$ Hunan Province Cooperation Innovation Center for Molecular Target New Drug Study, Hengyang 421001 , Hunan, P. R. China.

\section{Acknowledgements}

This work was supported by the National Natural Science Foundation of China (81573463) and Hunan Provincial Natural Science Foundation of China (2015JJ1024). The authors thank all the funding agencies supported this study and all the patients who participated in the study.

\section{Competing interests}

The authors declare that they have no competing interests.

Received: 12 April 2016 Accepted: 20 July 2016

Published online: 16 January 2017

\section{References}

1. Fiteni F, Vernerey D, Bonnetain F, Vaylet F, Sennelart $H$, Tredaniel J, et al. Prognostic value of health-related quality of life for overall survival in elderly non-small-cell lung cancer patients. Eur J Cancer. 2016;52:120-8.

2. Shi Y, Sun Y. Medical management of lung cancer: experience in China. Thorac Cancer. 2015;6(1):10-6.

3. Yan L, Xu L. Global efforts in conquering lung cancer in China. Chin J Cancer. 2015;34(7):320-2.

4. Wong IC, Ng YK, Lui VW. Cancers of the lung, head and neck on the rise: perspectives on the genotoxicity of air pollution. Chin J Cancer. 2014;33(10):476-80.

5. Chen W, Zheng R, Zeng H, Zhang S. The updated incidences and mortalities of major cancers in China, 2011. Chin J Cancer. 2015;34(11):502-7.

6. Yu JB, Soulos PR, Cramer LD, Decker RH, Kim AW, Gross CP. Comparative effectiveness of surgery and radiosurgery for stage I non-small cell lung cancer. Cancer. 2015;121(14):2341-9.

7. Moro-Sibilot D, Audigier-Valette C, Merle P, Quoix E, Souquet PJ, Barlesi F, et al. Non-small cell lung cancer recurrence following surgery and perioperative chemotherapy: comparison of two chemotherapy regimens (IFCT-0702: a randomized phase 3 final results study). Lung Cancer. 2015;89(2):139-45.

8. Powrozek T, Mlak R, Krawczyk P, Homa I, Ciesielka M, Koziol P, et al. The relationship between polymorphisms of genes regulating DNA repair or cell division and the toxicity of platinum and vinorelbine chemotherapy in advanced NSCLC patients. Clin Transl Oncol. 2016;18(2):125-31.

9. Yin JY, Meng XG, Qian CY, Li XP, Chen J, Zheng Y, et al. Association of positively selected elF3a polymorphisms with toxicity of platinum-based chemotherapy in NSCLC patients. Acta Pharmacol Sin. 2015;36(3):375-84.

10. Cao S, Wang C, Ma H, Yin R, Zhu M, Shen W, et al. Genome-wide association study on platinum-induced hepatotoxicity in non-small cell lung cancer patients. Sci Rep. 2015;5:11556.

11. Genestreti G, Di Battista M, Cavallo G, Bartolotti M, Brandes AA. Maintenance therapy in non-small cell lung cancer. Expert Rev Anticancer Ther. 2015;15(7):839-46. 
12. Germann MW, Johnson CN, Spring AM. Recognition of damaged DNA: structure and dynamic markers. Med Res Rev. 2012;32(3):659-83.

13. Perry JR, Hsu YH, Chasman DI, Johnson AD, Elks C, Albrecht E, et al. DNA mismatch repair gene MSH6 implicated in determining age at natural menopause. Hum Mol Genet. 2014;23(9):2490-7.

14. Fukuhara S, Chang I, Mitsui Y, Chiyomaru T, Yamamura S, Majid S, et al. DNA mismatch repair gene MLH1 induces apoptosis in prostate cancer cells. Oncotarget. 2014;5(22):11297-307.

15. Heinen CD. Translating mismatch repair mechanism into cancer care. Curr Drug Targets. 2014;15(1):53-64.

16. Roesner LM, Mielke C, Fähnrich S, Merkhoffer Y, Dittmar KE, Drexler HG et al. Stable expression of MutLy in human cells reveals no specific response to mismatched DNA, but distinct recruitment to damage sites. J Cell Biochem. 2013;114(10):2405-14.

17. Buermeyer AB, Deschenes SM, Baker SM, Liskay RM. Mammalian DNA mismatch repair. Annu Rev Genet. 1999;33:533-64.

18. Peltomaki P. Deficient DNA mismatch repair: a common etiologic factor for colon cancer. Hum Mol Genet. 2001;10(7):735-40.

19. Larrea AA, Lujan SA, Kunkel TA. SnapShot: DNA mismatch repair. Cell. 2010;141(4):730.e1.

20. Banasik M, Sachadyn P. Conserved motifs of MutL proteins. Mutat Res. 2014;769:69-79.

21. Garcia-Tello A, de Fata FR, Andres G, Ropero S, Lopez JI, Angulo JC. DNA repair genes and prognosis in sporadic forms of urothelial carcinoma of the upper urinary tract. Actas Urol Esp. 2014;38(9):600-7.

22. Scarbrough PM, Weber RP, Iversen ES, Brhane Y, Amos CI, Kraft P, et al. A cross-cancer genetic association analysis of the DNA repair and DNA damage signaling pathways for lung, ovary, prostate, breast, and colorectal cancer. Cancer Epidemiol Biomark Prev. 2016;25(1):193-200.
23. $\mathrm{Xu} \mathrm{XL}$, Yao YL, Xu WZ, Feng JG, Mao WM. Correlation of MSH3 polymorphisms with response and survival in advanced non-small cell lung cancer patients treated with first-line platinum-based chemotherapy. Genet Mol Res. 2015;14(2):3525-33.

24. Cooley N, Elder RH, Povey AC. The effect of Msh2 knockdown on methylating agent induced toxicity in DNA glycosylase deficient cells. Toxicology. 2010;268(1-2):111-7.

25. Tseng-Rogenski SS, Hamaya Y, Choi DY, Carethers JM. Interleukin 6 alters localization of hMSH3, leading to DNA mismatch repair defects in colorectal cancer cells. Gastroenterology. 2015;148(3):579-89.

26. Bawa S, Xiao W. A single amino acid substitution in MSH5 results in DNA alkylation tolerance. Gene. 2003;315:177-82.

27. Yin JY, Huang Q, Zhao YC, Zhou HH, Liu ZQ. Meta-analysis on pharmacogenetics of platinum-based chemotherapy in non small cell lung cancer (NSCLC) patients. PLoS ONE. 2012;7(6):e38150.

28. Chen J, Yin J, Li X, Wang Y, Zheng Y, Qian C, et al. WISP1 polymorphisms contribute to platinum-based chemotherapy toxicity in lung cancer patients. Int J Mol Sci. 2014;15(11):21011-27.

29. Wang Y, Yin JY, Li XP, Chen J, Qian CY, Zheng Y, et al. The association of transporter genes polymorphisms and lung cancer chemotherapy response. PLoS ONE. 2014;9(3):e91967.

30. Doherty JA, Sakoda LC, Loomis MM, Barnett MJ, Julianto L, Thornquist $M D$, et al. DNA repair genotype and lung cancer risk in the beta-carotene and retinol efficacy trial. Int J Mol Epidemiol Genet. 2013;4(1):11-34.

31. Vogelsang M, Paccez JD, Schafer G, Dzobo K, Zerbini LF, Parker MI. Aberrant methylation of the MSH3 promoter and distal enhancer in esophageal cancer patients exposed to first-hand tobacco smoke. J Cancer Res Clin Oncol. 2014;140(11):1825-33

\section{Submit your next manuscript to BioMed Central and we will help you at every step:}

- We accept pre-submission inquiries

- Our selector tool helps you to find the most relevant journal

- We provide round the clock customer support

- Convenient online submission

- Thorough peer review

- Inclusion in PubMed and all major indexing services

- Maximum visibility for your research

Submit your manuscript at www.biomedcentral com/submit 